\section{GEOMAGNETIC REVERSALS}

\section{Long Term Pattern?}

from our Geomagnetism Correspondent BEFORE the discovery of geomagnetic field reversals and the elucidation of the late Cainozoic polarity-time scale, the periodicities of known field variations ranged from seconds (external field effects) through centuries (secular variations of the non-dipole field generally in the range $10^{2}$ to $10^{3}$ years) to tens of thousands of years (dipole variations). The discovery in the 1950s and 1960s of variations having periods of millions or even tens of millions of years was, for obvious reasons, unexpected; though the improvement in both the quantity and quality of palaeomagnetic data has amply confirmed their reality since.

But do even longer periodicities exist? There would seem to be no $a$ priori reasons why not, though in view of the wide time coverage of data required for the successful detection of such variations the difficulties involved in the search are obvious. McElhinny (Science, 172, 157; 1971), however, has now collected together and analysed all the palaeomagnetic directional data for the Phanerozoic (actually 1,094 investigations) and finds that there do indeed seem to be field variations having periodicities of hundreds of millions of years.

The quantity that McElhinny has found significant is the relative proportions of normally and reversely magnetized rocks within the various geological epochs. During the Upper Tertiary, normal and reversed rocks apparently came upon the scene in equal proportions - the classic fraction which is used, among other things, as evidence for field reversal as opposed to self-reversal. In the Lower Tertiary there was a slight preponderance of reversed ( 55 per cent) over normal (45 per cent). The Upper Cretáceous, on the other hand. saw a violent lurch from normality (about 75 per cent) which had apparently lasted since the Permo-Triassic. Between the Silurian and Permian in one direction and the Silurian and Cambrian in the other the field was apparently more reversed than normal, although around the Silurian itself there was a 50-50 interval. From the Middle Carboniferous to the Lower Permian there was a period when hardly any normally magnetized rocks emerged at all--presumably a reflexion of the long Kiaman magnetic interval. In summary, the Earth's magnetic field was predominantly normal during the Mesozoic and predominantly reversed during the Palaeozoic. The "periodicity" of this variation (only one "period" can be seen, of course) is thus about $350-400$ million years.

According to McElhinny, the pro- pontion of mixed results (palaeomagnetic results involving both normal and reversed polarities) within any given geological epoch may be taken as a measure of reversal frequency-the greater the reversal frequency the more likely a palaeomagnetic data set is to contain both polarities. From plotting the mixed polarity proportion as a function of time throughout the Phanerozoic it then becomes clear that reversals were rare during the Upper Carboniferous and Permian (the long reversed Kiaman interval) and during the Upper Ordovician and Silurian. The greatest reversal frequencies, on the other hand, seem to have occurred during the Upper Cambrian and Lower Ordovician, the Lower and Middle Devonian and the Upper Tertiary-the third of these having been amply confirmed by sea floor spreading data.

Perhaps a surprising point to emerge from the analysis, however, is that of the 1,094 Phanerozoic palaeomagnetic studies 44 per cent represent normal rocks and 56 per cent represent reversed rocks. If the Tertiary is excluded these figures become 43 per cent and 57 per cent, respectively. At this level of analysis therefore the commonly stated view, supposedly based on experimental data, that rock polarities taken altogether are evenly divided seems to be invalidated.
MAMMALIA Cape Lion Skull

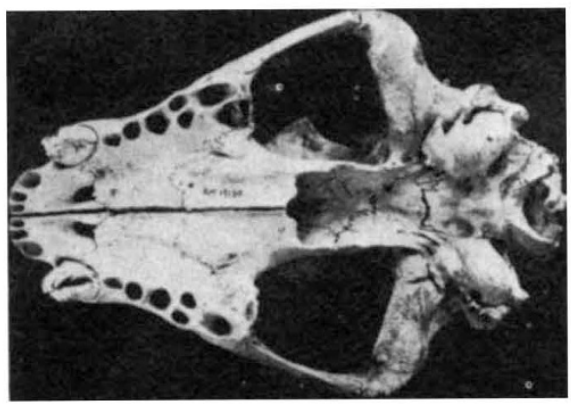

The Cape lion, Panthera leo melanochaita, is known only by its name and a few bones preserved in museums around the world; of these specimens only three are skulls. One of these is now briefly described by $\mathbf{J}$. Meester of the Mammal Research Unit at the University of Pretoria (Ann. Transv. Mus., 27, $27 ; 1971)$. It was dug up in the early 1960s at Betty's Bay on the southern Cape coast and was later presented to the Kaffrarian Museum in King William's Town. It lacks both its lower jaw and all its upper teeth except the canines, but it shares its distinctive broad muzzle - the feature which distinguishes it from living lions-with a skull recovered earlier from Murraysburg in the Cape.

\title{
Transformation and Autoagglutination
}

WITH so much attention being focused these days on the changes in the surfaces of cells after they have been transformed to malignancy by tumour viruses and other agents, any new parameter, such as that reported in next week's Nature New Biology by Edwards, Campbell and Williams, which reveals differences between the surfaces of transformed and untransformed cells is sure of a warm welcome.

Edwards and his colleagues have discovered an extremely simple method for distinguishing untransformed cells of the BHK line from these cells transformed by polyoma virus. When suspensions of untransformed BHK cells, produced by freeing cells from the glass or plastic dishes in which they are grown by exposure to small amounts of trypsin, are gently swirled in Hanks solution (a defined mineral medium), they adhere to one another and they can be measured easily with a Coulter particle counter. By contrast, when BHK cells transformed by polyoma virus are treated in an identical manner little or no aggregation can be detected.

After repeated serial passages, cloned untransformed and transformed BHK cells maintain this different pattern of autoagglutination, and only by allowing transformed cells to grow into very dense cultures did Edwards et al. find it possible to increase the extent to which they adhere to each other. This pattern of aggregation is, of course, precisely the reverse of the cell agglutination brought about by plant agglutinins such as Concanavalin $\mathrm{A}$ and wheat germ agglutinin; transformed cells are more susceptible than untransformed to agglutination by these agents.

It will be interesting to learn whether the pattern of autoagglutination shown by BHK cells and their polyoma transformants is common to other cell lines and to cells transformed by other viruses. It will be equally interesting to see whether and how all the various surface changes following transformation, which can be detected by a variety of methods, are interrelated. In the meantime, Edwards et al. have provided another test, remarkable for its simplicity, for the transformed cell phenotype, and the trait they assay, cell adhesion, may be of importance to malignancy in vivo. 